\title{
A Novel Preparation Method for Microspheres of Water Soluble Polymers Using Polypropyleneglycol as the Dispersion Medium
}

\author{
Toshinobu Seki, ${ }^{*}, a$ Katsunori Shinohara, ${ }^{b}$ Naoko Kato, ${ }^{b}$ Masaki Uchida, ${ }^{b}$ Hideshi Natsume, ${ }^{b}$ \\ Kazuhiro Morimoto, ${ }^{a}$ and Kazuhiko JuNI ${ }^{b}$ \\ ${ }^{a}$ Hokkaido Pharmaceutical University School of Pharmacy; 7-1 Katsuraoka-cho, Otaru, Hokkaido 047-0264, Japan: and \\ ${ }^{b}$ Faculty of Pharmaceutical Sciences, Josai University; 1-1 Keyakidai, Sakado, Saitama 350-0295, Japan. \\ Received October 3, 2006; accepted December 22, 2006; published online January 5, 2007
}

\begin{abstract}
Polypropyleneglycol (PPG) was used as a dispersion medium for the preparation of microspheres (MS) consisting of starch, gelatin, whey protein or dextran. Aqueous solutions of the polymers were dispersed in PPG at various initial temperatures and then the systems were cooled to $0.5^{\circ} \mathrm{C}$ to allow water in the dispersed phase to dissolve in PPG. The particle size of the starch-MS was dependent on the initial temperature of PPG in the preparation process. There were two different processes for particle generation in the procedure. One of them was via the formation of a temporary emulsion during the early phase of dispersion of the aqueous polymer solution into PPG. The other was via the stable emulsion in which the aqueous polymer solution was dispersed in water-saturated PPG. The particle size generated in the former process was dependent on the initial temperature: a high temperature gave large particles but a low temperature gave small particles, while that in the latter process was temperature-independent. This preparation method for MS will be useful for the formulation of heat-sensitive material, such as protein-containing drugs.
\end{abstract}

Key words microsphere; polypropyleneglycol; starch; gelatin; whey protein; dextran

Microspheres (MS) are useful as drug carriers to improve the performance of therapeutic systems. For example, stable release by a valve and guaranteed delivery to the lung by a metered dose inhaler or dry powder inhaler formulations can be achieved using size-controlled spherical MS, ${ }^{1)}$ and the therapeutic drugs entrapped in MS and, when injected vascularly, can distribute to specific organs or tissues depending on their size., ${ }^{2,3)}$ The choice of the matrix material and size control of the MS are the most important factors in designing any therapeutic system. Lipophilic polymer esters such as poly(lactic-co-glycolic acid) are popular materials and exhibit prolonged drug release. On the other hand, hydrophilic polymers can be used for controlled release over shorter periods and may be better at entrapping MS for water-soluble drugs compared with lipophilic polymers. ${ }^{4)}$

MS consisting of hydrophilic polymers, such as proteins and polysaccharides, can be prepared by emulsion-evaporation and spray-drying. ${ }^{5-7)}$ Water is a good solvent for such polymers during the preparation processes. In most cases, cross-linking agents are used to ensure particle generation. ${ }^{8}$ However, heating to evaporate water and addition of crosslinking agents may not be good for the stability of therapeutic drugs in MS. ${ }^{9,10)}$ Although gelatin MS can be prepared in cooling processes to promote gel formation, cross-linking agents such as glutaraldehyde are needed to control drug release from the resulting MS. ${ }^{11)}$ A novel preparation method for MS consisting of water soluble polymers, which can be applied to various types of polymers and does not require heating and cross-linking reactions during the preparation process, will be useful for the preparation of MS containing sensitive materials, such as protein drugs.

In the present study, polypropyleneglycol (PPG) was used as a dispersion medium for the preparation of MS consisting of water-soluble polymers. PPG is hydrophobic at high temperatures but hydrophilic and freely soluble in water at low temperatures. Therefore, the PPG-water system forms two liquid phases like an emulsion at a high temperature and the system changes to a liquid phase on cooling. This temperature-dependent property of PPG can be used to remove water from aqueous polymer solutions dispersed in PPG to form solid polymer particles. Soluble starch is used mainly as the model water-soluble polymer. Gelatin, whey protein and dextran have also been used for MS preparation.

\section{Experimental}

Materials Polypropyleneglycol (diol type 700, PPG) and soluble starch were purchased from Wako Pure Chemical (Osaka). Whey protein isolate (WPI) was kindly supplied by Snow Brand Milk Products (Tokyo). Dextran T70 and gelatin were purchased from Pharmacia Biotech (Uppsala, Sweden) and Nitta Gelatin (Osaka), respectively. All other chemicals were of reagent grade and used as received.

Procedure for Microsphere Preparation Water soluble polymers (starch, gelatin, WPI or dextran T70) were initially dissolved in water (5$10 \%)$ at $60^{\circ} \mathrm{C}$ for the aqueous phase. The aqueous solution $(3-10 \mathrm{~g})$ was added to PPG $(41.8 \mathrm{~g})$, mixed using a paddle with triple wings $(\mathrm{d}=35 \mathrm{~mm})$ at $400 \mathrm{rpm}$ and $20-60^{\circ} \mathrm{C}$ in a $100 \mathrm{ml}$ beaker, and then the mixing was continued for $0.5 \mathrm{~min}-2 \mathrm{~h}$. The mixture was cooled to $0.5^{\circ} \mathrm{C}$, and the resulting MS were collected on filter paper $(0.6 \mu \mathrm{m}$, glass fiber filter paper, ADVANTEC, Tokyo) $30 \mathrm{~min}$ after cooling and then washed with ethanol or acetone. The MS were dried at room temperature under reduced pressure for $18 \mathrm{~h}$. The yield of MS was always over $90 \%$.

Scanning Electron Microphotography Observations and Size Determination of MS MS were platinum-palladium-coated using an ion-coater (1B-3, Eiko, Tokyo) and were observed using scanning electron micrography (S-430, Hitachi, Tokyo) at $20 \mathrm{kV}$ and the particle size was determined as the Green diameter manually. The length-number mean and standard deviation of the diameter for $300-600$ particles were calculated.

\section{Results}

Phase Diagram for the PPG-Water System Figure 1 shows the phase diagram for the PPG-water system. The solubility curve was obtained based on optical observations of PPG-water mixtures having different compositions at various temperatures. The lower consolute temperature of the system is $4{ }^{\circ} \mathrm{C}$ at $50 \%$ PPG and the system forms two liquid phases in the upper region of the solubility curve.

Preparation of Starch MS at a Weight Ratio of PPGAqueous Phase $=80.7: 19.3$ Firstly, starch MS were pre- 


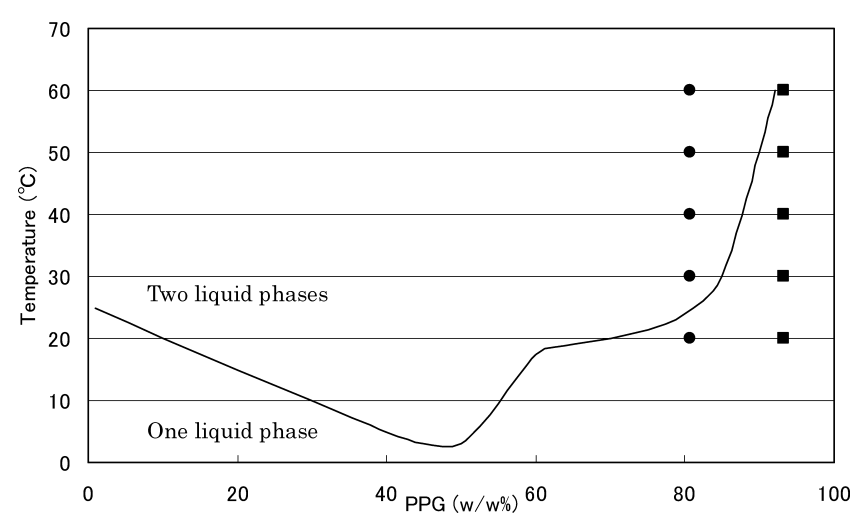

Fig. 1. Phase Diagram for the PPG-Water System with Lower Consolute Temperature

Points $(\boldsymbol{\square})$ are initial conditions for the preparation of starch MS $(\bullet$, PPG : aqueous phase $=80.7: 19.3 ; \mathbf{\square}, \mathrm{PPG}:$ aqueous phase=93.3:6.7).
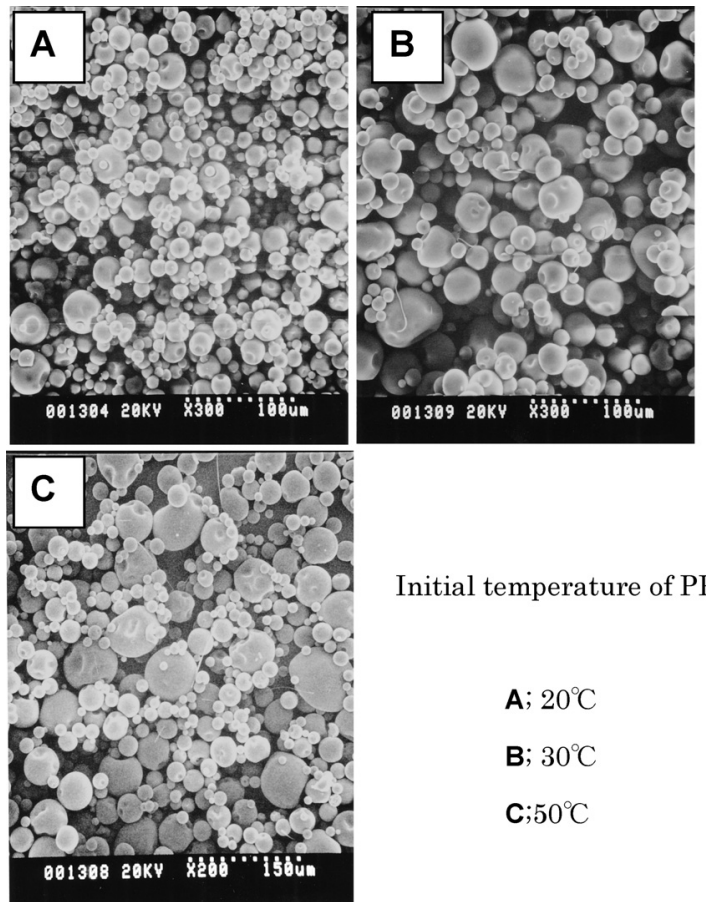

Initial temperature of $\mathrm{PPG}$
A; $20^{\circ} \mathrm{C}$
B; $30^{\circ} \mathrm{C}$
C; $50^{\circ} \mathrm{C}$

Fig. 2. Scanning Electron Microphotographs of Starch MS Prepared at a PPG-Aqueous Phase $=80.7: 19.3$

Starch was preliminarily dissolved in water $(7 \%)$ at $60^{\circ} \mathrm{C}$ for the aqueous phase. The starch solution $(10 \mathrm{~g})$ was added to PPG $(41.8 \mathrm{~g})$ at $20^{\circ} \mathrm{C}(\mathrm{A}), 30^{\circ} \mathrm{C}(\mathrm{B})$ or $50^{\circ} \mathrm{C}(\mathrm{C})$, and then mixed at $400 \mathrm{rpm}$ for $1 \mathrm{~min}$. The mixture was cooled to $0.5^{\circ} \mathrm{C}$, and the resulting MS were collected on filter paper $30 \mathrm{~min}$ after cooling and then washed with ethanol.

pared using a system consisting of PPG:aqueous phase $=$ 80.7 : 19.3 at various initial temperatures $\left(20-60^{\circ} \mathrm{C}\right)$ of $\mathrm{PPG}$ (refer to in Fig. 1). The system forms two liquid phases above $25^{\circ} \mathrm{C}$ and looks like an emulsion following mixing at $400 \mathrm{rpm}$. A starch solution $(7 \%, 10 \mathrm{~g})$ was added to PPG $(41.8 \mathrm{~g})$, mixed at $400 \mathrm{rpm}$, and then the mixture was cooled to $0.5^{\circ} \mathrm{C} 1 \mathrm{~min}$ after addition of the aqueous phase. The resulting MS collected $30 \mathrm{~min}$ after cooling were spherical with a smooth surface independently of the initial temperature of the PPG (Fig. 2). The mean diameter of the starch MS was dependent on the initial temperature, and large particles were obtained at a high initial temperature and small particles were obtained at a low initial temperature ( $O$ in Fig. 3 ).

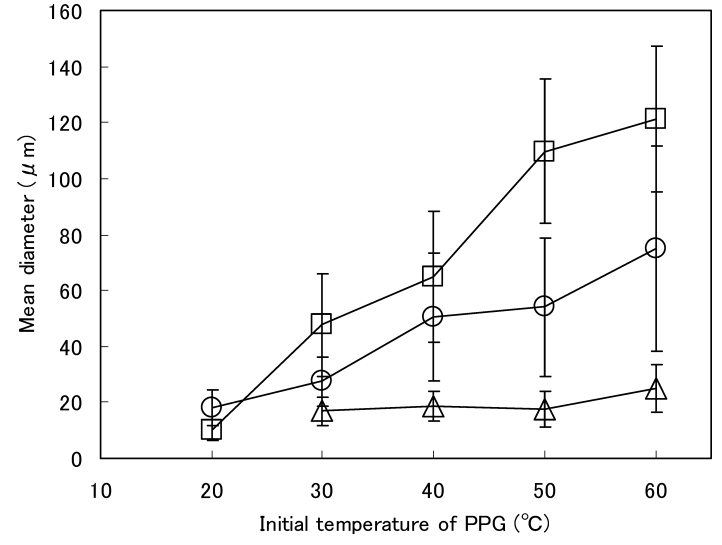

Fig. 3. Relationship between the Initial Temperature of PPG in the Starch MS Preparation and the Mean Diameter of the Resulting MS

Vertical bars represent the S.D. $\bigcirc$, PPG : starch solution $=80.7: 19.3 ; \square$, PPG : starch solution $=93.3: 6.7 ; \triangle$, water saturated PPG-starch solution systems (final weight ratio of PPG : aqueous phase $=80.7: 19.3$ ).

This was an impressive result, and the preparation at the initial temperature of $20^{\circ} \mathrm{C}$ gave spherical particles (Fig. 2A), although PPG were completely soluble in water under these conditions. Stable emulsion formation might not necessarily be required for the generation of spherical particles during the preparation process.

Preparation of Starch MS at a Weight Ratio of PPGAqueous Phase=93.3 : 6.7 In order to examine the formation of spherical particles not via emulsion formation, starch MS were prepared in a system consisting of PPG : aqueous phase $=93.3: 6.7$ at various initial temperatures $\left(20-60^{\circ} \mathrm{C}\right)$ of PPG (refer to $\mathbf{~ i n ~ F i g . ~ 1 ) . ~ M S ~ p r e p a r e d ~ u s i n g ~ t h e ~ s t a r c h ~}$ solution (7\%, $3 \mathrm{~g})$ and PPG (41.8 g) were also spherical having a smooth surface independently of the initial temperature of PPG (Fig. 4). The mean diameter of the MS was also dependent on the initial temperature and the effect of temperature on size was greater in the $93.3: 6.7$ system ( $\square$ in Fig. 3) than in the $80.7: 19.3$ system ( $\bigcirc$ in Fig. 3). The spherical shape of the particles suggests formation of a temporary emulsion within $1 \mathrm{~min}$ of addition of the aqueous phase. The preparation process after mixing PPG and the starch solution was modified in order to determine when the solid particles were generated; i.e. the mixing period was prolonged and in some cases the cooling process was canceled. Figure 5 shows the shape of starch MS prepared using the modified procedures. The size of the MS was independent of the mixing time at $60^{\circ} \mathrm{C}$ and similar particles were generated without cooling to $0.5^{\circ} \mathrm{C}$. These results suggest that the temporary emulsion changed to an MS suspension isothermally within $1 \mathrm{~min}$.

Preparation of Starch MS Using Water Saturated PPG In the preparation of MS using PPG: starch solution= $80.7: 19.3$, some of the water in the aqueous solution dissolves in the PPG isothermally at each initial temperature. In order to avoid this initial dissolution of water in PPG, PPG saturated with water beforehand was used for the preparation of starch MS. The water saturated PPG solutions were prepared by addition of $6 \mathrm{~g}, 5 \mathrm{~g}, 4 \mathrm{~g}$ and $3 \mathrm{~g}$ water to $41.8 \mathrm{~g}$ PPG at an initial temperature of $30^{\circ} \mathrm{C}, 40^{\circ} \mathrm{C}, 50^{\circ} \mathrm{C}$ and $60^{\circ} \mathrm{C}$ and $4 \mathrm{~g}, 5 \mathrm{~g}, 6 \mathrm{~g}$ and $7 \mathrm{~g}$ starch solutions (7\%) were dispersed in the PPG solutions to prepare MS at an initial temperature of $30^{\circ} \mathrm{C}, 40^{\circ} \mathrm{C}, 50^{\circ} \mathrm{C}$ and $60^{\circ} \mathrm{C}$, respectively. Spherical parti- 

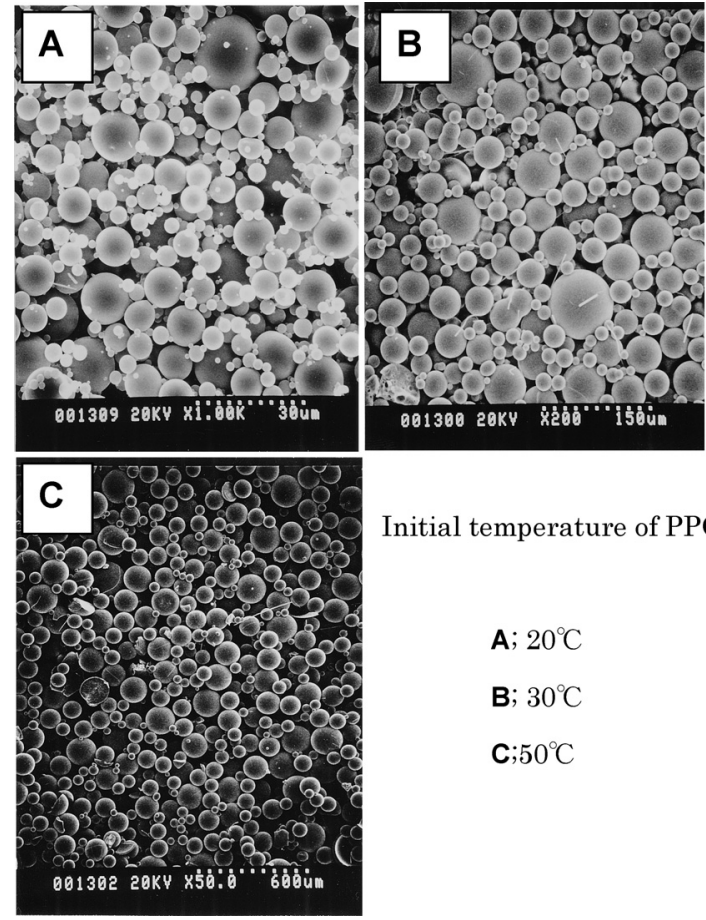

Initial temperature of $\mathrm{PPG}$

A; $20^{\circ} \mathrm{C}$

B; $30^{\circ} \mathrm{C}$

C; $50^{\circ} \mathrm{C}$

Fig. 4. Scanning Electron Microphotographs of Starch MS Prepared at a PPG-Aqueous Phase $=93.3: 6.7$

The starch solution $(3 \mathrm{~g})$ was added to PPG $(41.8 \mathrm{~g})$ at $20^{\circ} \mathrm{C}(\mathrm{A}), 30^{\circ} \mathrm{C}(\mathrm{B})$ or $50^{\circ} \mathrm{C}$ (C), and then mixed at $400 \mathrm{rpm}$ for $1 \mathrm{~min}$. The resulting MS were collected $30 \mathrm{~min}$ after cooling to $0.5^{\circ} \mathrm{C}$ followed by washing with ethanol.
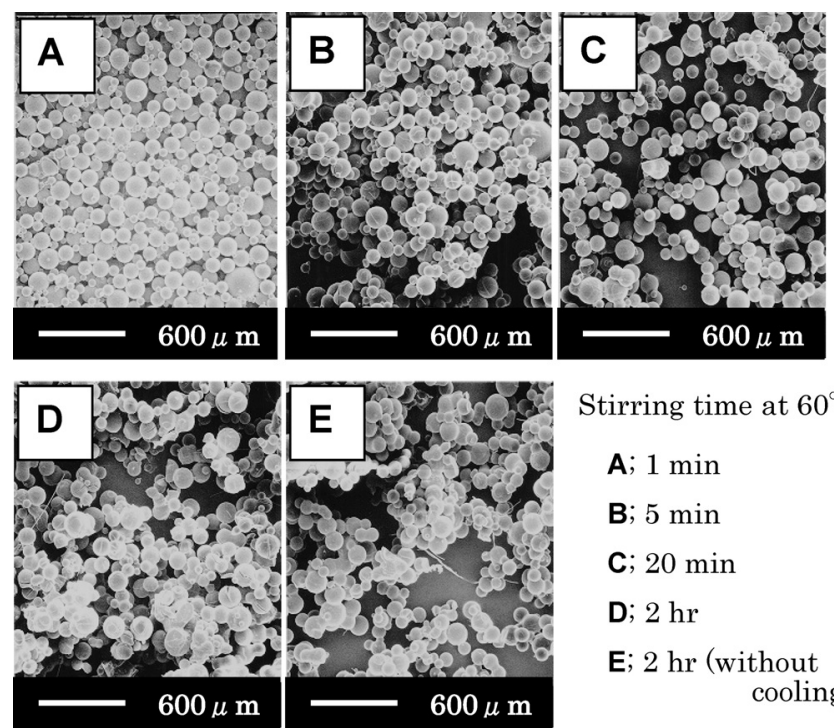

Stirring time at $60^{\circ} \mathrm{C}$
A; $1 \mathrm{~min}$
B; $5 \mathrm{~min}$
C; $20 \mathrm{~min}$
D; $2 \mathrm{hr}$
E; 2 hr (without cooling)

Fig. 5. Scanning Electron Microphotographs of Starch MS Prepared at a PPG-Aqueous Phase $=93.3: 6.7$ and an Initial PPG Temperature of $60^{\circ} \mathrm{C}$

The starch solution $(3 \mathrm{~g})$ was added to PPG $(41.8 \mathrm{~g})$ at $60^{\circ} \mathrm{C}$, and then mixed at $400 \mathrm{rpm}$ for $1 \mathrm{~min}(\mathrm{~A}), 5 \mathrm{~min}$ (B), $20 \mathrm{~min}$ (C) or $2 \mathrm{~h}$ (D) before cooling to $0.5^{\circ} \mathrm{C}$. The resulting MS were collected and washed with ethanol. In the case of sample (E) alone, the resulting MS were collected after $2 \mathrm{~h}$ mixing at $60^{\circ} \mathrm{C}$ without cooling.

cles were obtained at each initial temperature of PPG without any aggregation (Fig. 6) and the mean diameter of the MS was independent of the initial temperature ( $\triangle$ in Fig. 3).

Preparation of Gelatin, WPI and Dextran MS The MS preparation method using PPG was applied to other water soluble polymers. Gelatin solution $(10 \%, 10 \mathrm{~g})$, WPI solution $(5 \%, 10 \mathrm{~g})$ and dextran T70 solution $(7 \%, 5 \mathrm{~g})$ were
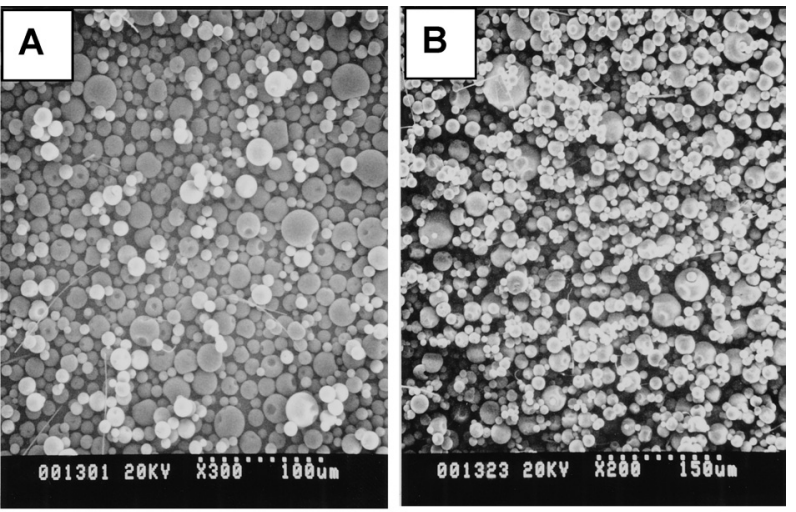

Initial temperature of water saturated PPG

$$
\text { A; } 30^{\circ} \mathrm{C} \quad \text { B; } 50^{\circ} \mathrm{C}
$$

Fig. 6. Scanning Electron Microphotographs of Starch MS Prepared in Water Saturated PPG-Starch Solution Systems

The starch solution $\left(7 \%: 30^{\circ} \mathrm{C}, 4 \mathrm{~g} ; 50^{\circ} \mathrm{C}, 6 \mathrm{~g}\right)$ was added to a mixture of PPG $(41.8 \mathrm{~g})$ and water $\left(30^{\circ} \mathrm{C}, 6 \mathrm{~g} ; 50^{\circ} \mathrm{C}, 4 \mathrm{~g}\right)$ at $30^{\circ} \mathrm{C}(\mathrm{A})$ or $50^{\circ} \mathrm{C}(\mathrm{B})$, and mixed at $400 \mathrm{rpm}$ for $1 \mathrm{~min}$. The resulting MS were collected $30 \mathrm{~min}$ after cooling to $0.5^{\circ} \mathrm{C}$ and then washed with ethanol.
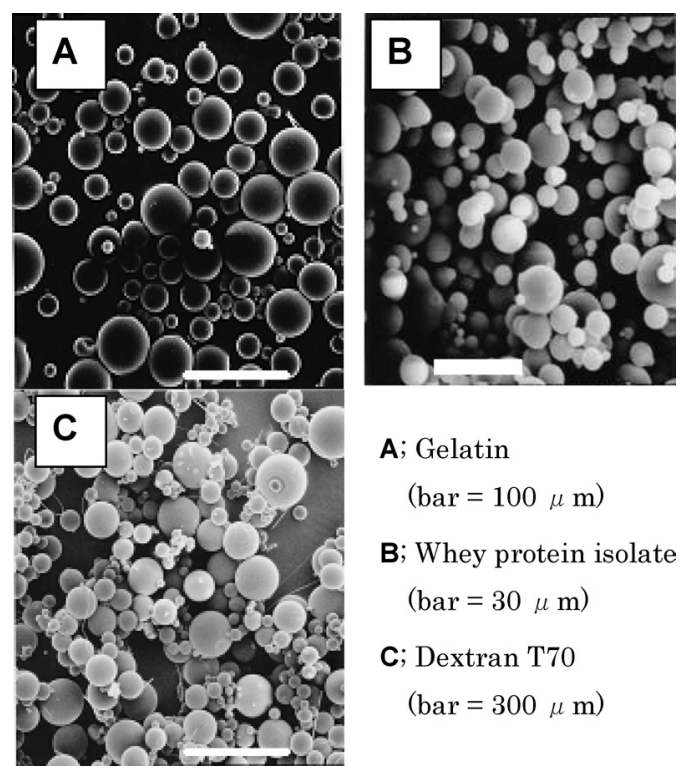

\section{A; Gelatin \\ $($ bar $=100 \mu \mathrm{m})$}

B; Whey protein isolate

(bar $=30 \mu \mathrm{m})$

C; Dextran T70

$($ bar $=300 \mu \mathrm{m})$

Fig. 7. Water-Soluble Polymer MS Prepared in PPG-Water Systems

Polymer solutions (A, gelatin $10 \%, 10 \mathrm{~g}$; B, whey protein isolate $5 \%, 10 \mathrm{~g}$; C, dextran $\mathrm{T} 707 \%, 5 \mathrm{~g})$ were added to $\mathrm{PPG}(41.8 \mathrm{~g})$ at $45^{\circ} \mathrm{C}(\mathrm{A}), 30^{\circ} \mathrm{C}(\mathrm{B})$ and $50^{\circ} \mathrm{C}(\mathrm{C})$, respectively, and then mixed at $400 \mathrm{rpm}$ for $1 \mathrm{~min}(\mathrm{~A}, \mathrm{~B})$ or $0.5 \mathrm{~min}(\mathrm{C})$. The MS were collected $30 \mathrm{~min}$ after cooling to $0.5^{\circ} \mathrm{C}$ and washed with acetone (A) or ethanol (B, C).

added to PPG $(41.8 \mathrm{~g})$ at $45^{\circ} \mathrm{C}, 30^{\circ} \mathrm{C}$ and $50^{\circ} \mathrm{C}$, respectively, and then they were mixed at $400 \mathrm{rpm}$ for $1 \mathrm{~min}$ (for gelatin and WPI) or $0.5 \mathrm{~min}$ (for dextran). The MS were collected $30 \mathrm{~min}$ after cooling to $0.5^{\circ} \mathrm{C}$ and then washed with acetone (for gelatin) or ethanol (for WPI and dextran). Figure 7 shows the shape of the gelatin, WPI and dextran-MS. All are spherical with a smooth surface.

\section{Discussion}

In this study, PPG was used as a dispersion medium for the preparation of MS consisting of water-soluble polymers. There were two different processes for the generation of particles in the preparation of starch-MS. One of them was a process using a temporary emulsion giving spherical parti- 

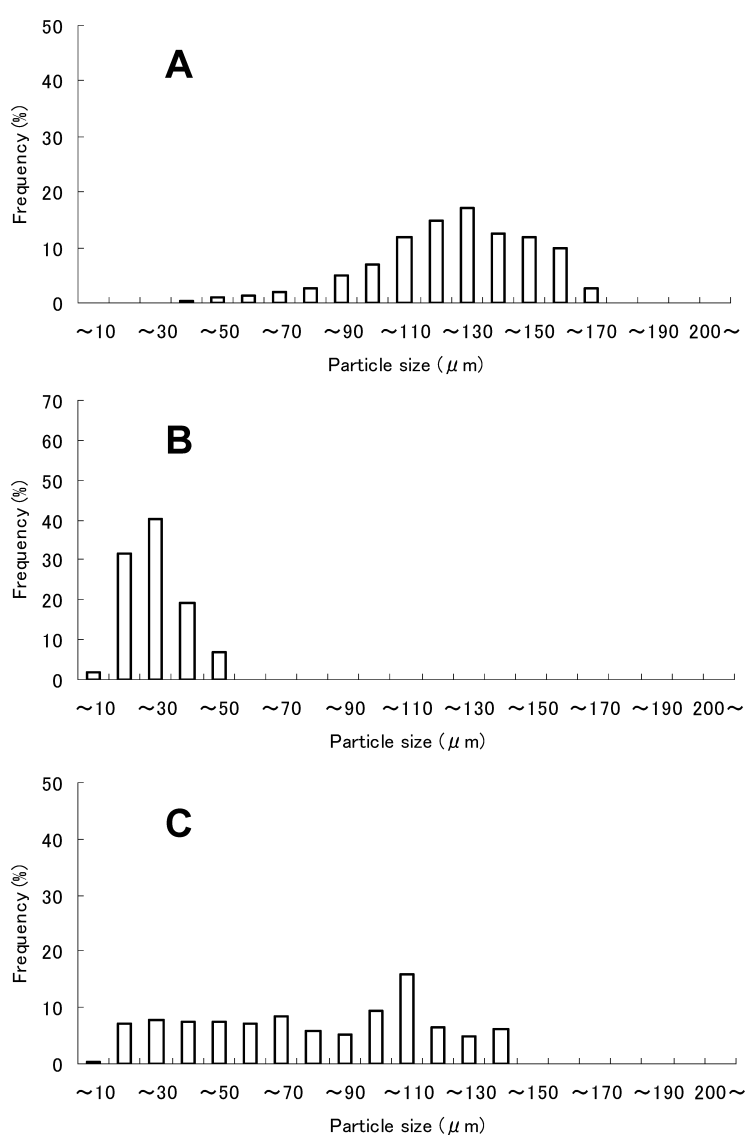

Fig. 8. Particle Size Distribution of Starch MS Prepared at an Initial PPG Temperature of $60^{\circ} \mathrm{C}$

(A), PPG-aqueous phase $=93.3: 6.7$; (B), Water saturated PPG-aqueous phase; $(\mathrm{C})$, PPG-aqueous phase $=80.7: 19.3$. The starch solution (A and B, $3 \mathrm{~g} ; \mathrm{C}, 10 \mathrm{~g}$ ) was mixed with PPG (A and C, 41.8g) or water-saturated PPG (B, 41.8 g PPG mixed with $7 \mathrm{~g}$ water) for $1 \mathrm{~min}$, and then the mixture was cooled to $0.5^{\circ} \mathrm{C}$.

cles with various size ranges. Since solid particles could be formed without cooling during the process, the temporary emulsion was generated during the initial phase of the isothermal dissolution of water in PPG. The size of the resulting particles was dependent on the initial temperature of the dispersion medium: a high temperature gave large particles and a low temperature gave small particles ( $\square$ in Fig. 3). This result suggests that the droplet size of the temporary emulsion is dependent on the hydrophilicity of PPG. At a high temperature, the relatively hydrophobic PPG gave large droplets, while at a low temperature hydrophilic PPG gave small droplets during the initial phase of the dispersion. Another process for particle generation involved stable emulsions of aqueous polymer solution in water-saturated PPG. The size of the resulting particles was independent of the initial temperature of the PPG ( $\triangle$ in Fig. 3 ). The droplet size of the emulsion during the initial phase of the dispersion depended on the hydrophilicity of the PPG phase. During the cooling process, the droplet size could be reduced and then the droplets could be converted to solid particles at $25^{\circ} \mathrm{C}$. In the preparation of starch-MS with PPG:aqueous phase $=$ $80.7: 19.3$, the mean diameter of the resulting particles was between that in the PPG:aqueous polymer solution= $93.3: 6.7$ system and the water-saturated PPG : aqueous polymer solution system for each initial temperature $(\bigcirc$ in Fig. $3)$. Figure 8 shows the particle size distribution of starch MS prepared at an initial PPG temperature of $60^{\circ} \mathrm{C}$. In the preparation involving PPG: aqueous phase $=93.3: 6.7$ and watersaturated PPG, the resulting MS have a bell-shaped distribution, while in the preparation involving PPG:aqueous phase $=80.7: 19.3$, the resulting MS have a broad distribution. These findings mean that two different processes for particle generation occur in the PPG:aqueous phase $=$ 80.7 : 19.3 system simultaneously.

Particle size control is important for MS preparations. Modification of the stirring rate and addition of suitable surfactants are possible ways of controlling the size. ${ }^{12,13)}$ In our preparation method, the particle size was controlled by the initial temperature at a constant stirring rate without addition of any surfactants. Since surfactants sometimes affect the stability of active drugs in MS, ${ }^{14)}$ this surfactant-free preparation method is an advantage. In this study, we have shown that our method is applicable not only to starch but also gelatin, WPI and dextran. The applicability to a variety of watersoluble polymers is another advantage of our method. Studies of the stability and release of protein drugs entrapped in MS prepared by this method are underway.

\section{References}

1) Fiegel J., Fu J., Hanes J., J. Control. Release, 96, 411-423 (2004).

2) Kanke M., Simmons G. H., Weiss D. L., Bivins B. A., DeLuca P. P., J. Pharm. Sci., 69, 755-762 (1980).

3) Davis S. S., Illum L., Moghimi S. M., Davies M. C., Porter C. J. H., Muir I. S., J. Control. Release, 24, 157-163 (1993).

4) Seki T., Kawaguchi T., Endoh H., Ishikawa K., Juni K., Nakano M., J. Pharm. Sci., 79, 985-987 (1990).

5) Freitas S., Merkle H. P., Gander B., J. Control. Release, 102, 313-332 (2005).

6) Johansen P., Merkle H. P., Gander B., Eur. J. Pharm. Sci., 50, 413417 (2000).

7) Dandagi P. M., Mastiholimath V. S., Patil M. B., Gupta M. K., Int. J. Pharm., 307, 83-88 (2006).

8) Puri N., Kou J. H., Sinko P. J., J. Control. Release, 69, 53-67 (2000).

9) Weert M. V. D., Hennink W. E., Jiskoot W., Pharm. Res., 171159 1167 (2000).

10) Freitas S., Merkle H. P., Gander B., J. Control. Release, 95, 185-195 (2004).

11) Morimoto K., Chono S., Kosai T., Seki T., Tabata Y., J. Pharm. Pharmacol., 57, 839-844 (2005).

12) Uchida T., Goto S., Foster T. P., J. Pharm. Pharmacol., 47, 556-560 (1994).

13) Lee S. C., Oh J. T., Jang M. H., Chung S. I., J. Control. Release, 59, 123-132 (1999).

14) Tamber H., Johansen P., Merkle H. P., Gander B., Adv. Drug Deliv Rev., 57, 357-376 (2005). 